PREHOSPITAL CARE

\title{
Does initiation of an ambulance pre-alert call reduce the door to needle time in acute myocardial infarct?
}

\author{
S R Learmonth, A Ireland, C J Mckiernan, P Burton
}

Emerg Med J 2006;23:79-81. doi: 10.1136/emj.2004.022376

See end of article for
authors' affiliations
$\ldots \ldots \ldots \ldots \ldots \ldots \ldots \ldots . \ldots . \ldots$.
Correspondence to:
Sarah Learmonth, Flat 3/
3, 42 Minard Road,
Glasgow, G41 2HW;
sarah.learmonth@gmail.
com
Received
19 November 2004
In revised form
20 May 2005
Accepted for publication
7 June 2005

7 June 2005

\begin{abstract}
Objectives: To assess the effect an ambulance pre-alert call for patients with suspected acute myocardial infarction (AMI) would have on door to needle (DTN) times.

Methods: We carried out back to back audits of DTN times following the initiation of the pre-alert calls. Participants: All patients thrombolysed within the emergency department between July 2003 and April 2004 (inclusive).

Statistical analysis: Mean DTN times and time to ECG pre-change and post-change were compared using the Two sample $t$ test. The Fisher's exact test was used to compare pre-change and post-change proportions of patients seen within guideline times.

Results: In total, 73 patients were thrombolysed with 40 of these arriving by ambulance. Eighteen of these 40 were pre-change and 22 were post-change. Four patients were excluded. Fifty per cent of the prechange group had a DTN time of $<30$ minutes compared with $91 \%$ of the post-change group $(p=0.005$, Fisher's exact test). The phase one mean DTN time was found to be significantly greater than that for phase two (Two sample $t$ test, $\mathrm{p}=0.016 ; 95 \% \mathrm{Cl} 1.6$ to 14.6 ).

Conclusions: There was a significant reduction in DTN times after the introduction of the pre-alert call.
\end{abstract}

S everal randomised controlled trials have shown that morbidity and mortality associated with acute myocardial infarction (AMI) can be reduced by early thrombolysis. ${ }^{1-2}$ Other work has shown that paramedic electrocardiogram (ECG) interpretation and fast tracking of patients with myocardial infarction to a coronary care unit (CCU) reduces door to needle (DTN) times, ${ }^{3-5}$ as does thrombolysis in the emergency department. ${ }^{6}$

Currently our institution has a target of 30 minutes for $\mathrm{DTN}^{7}$ in $75 \%$ of cases and that an ECG should be carried out within 10 minutes of arrival.

Audits in both accident and emergency (A\&E) and the CCU unit indicated that improvements in the percentage thrombolysed within 30 minutes could be achieved. Previous work examined the reasons for delays and identified several factors: delays to initial ECG, the wide variety of clinical presentation, and the mode of arrival at the department. Audit data suggested that patients with AMI who were called in as a pre-alert priority one "stand-by" received the quickest thrombolysis. However, a survey of ambulance service personnel (personal communication, Special Studies Module "who is a standby", May 03) showed that there was a lack of consistency in which patients were called in as a stand-by.

The purpose of this study was to assess the change in practice that was initiated to try to improve the DTN times.

\section{METHODS}

Glasgow Royal Infirmary is a secondary and tertiary referral centre for acute cardiological intervention (including primary angioplasty), accepting patients from the West of Scotland region. The local catchment area is mainly urban with a population of 2500000 . The A\&E department sees approximately 68000 new patients per year and is part of the newly constructed acute services building, which includes the CCU. All immediate thrombolysis is carried out in the A\&E department. Although there are plans to introduce prehospital (paramedic) thrombolysis, currently this is not carried out.
Initial audit data for the five months before the changes were introduced (phase one) confirmed the need for intervention. Data were collected for an equivalent period post-intervention (phase two).

The ambulance service was asked to radio a pre-alert for all patients with chest pain as a "category 2 stand-by" in order that an immediate ECG could be obtained in resuscitation or monitored space depending on activity. The established practice of immediate medical review of the resulting ECG was continued.

The standard AMI audit form was completed for all patients who received thrombolysis and the data collected (during a 10 month study period) were subsequently analysed.

\section{Statistical analysis}

Statistical significance was defined as $p<0.05$ for Fisher's exact test and Two sample $t$ test.

\section{RESULTS}

Only patients who received thrombolysis in A\&E were included. Altogether, 77 patients were thrombolysed during the study period, although four of these patients were excluded from further analysis because of incompleteness of the data.

During phase one, 38 patients were thrombolysed, 18 of whom arrived by ambulance and 18 of whom self presented. The method of arrival could not be established from the case notes of two patients. Nine of the $18(50 \%)$ patients arriving by ambulance were thrombolysed within 30 minutes (table 1). Ten of the same $18(56 \%)$ had their first ECG carried out within 10 minutes, whereas six patients waited longer than 10 minutes, and the time to first ECG was not documented for two patients (table 2).

Abbreviations: $A \& E$, accident and emergency; $A M I$, acute myocardial infarct; CCU, coronary care unit; DTN, door to needle; ECG, electrocardiogram 
Table 1 Door to needle time (minutes) for patients pre (phase one) and post (phase two) intervention

\begin{tabular}{|c|c|c|c|c|c|c|}
\hline \multirow[b]{2}{*}{ Thrombolysis } & \multicolumn{3}{|l|}{1} & \multicolumn{3}{|l|}{2} \\
\hline & $\operatorname{Amb}(\%)$ & Self (\%) & Total (\%) & Amb (\%) & Self $(\%)$ & Total \\
\hline$\leqslant 20$ minutes & 5 & 9 & 14 & 13 & 7 & 20 \\
\hline $21-30$ minutes & 4 & 6 & 10 & 7 & 2 & 9 \\
\hline$>30$ minutes & 9 & 3 & 12 & 2 & 3 & 5 \\
\hline $\begin{array}{l}\text { Not } \\
\text { documented }\end{array}$ & 0 & 0 & 0 & 0 & 0 & 0 \\
\hline Total & 18 & 18 & 36 & 22 & 12 & 34 \\
\hline
\end{tabular}

During phase two, 35 patients were thrombolysed, 22 of whom arrived by ambulance and 13 of whom self presented. The method of arrival could not be established for one patient. Twenty of the 22 (91\%) patients arriving by ambulance were thrombolysed within 30 minutes (table 2). Twenty one of the same 22 (95\%) had their first ECG carried out within 10 minutes, while the time to ECG was not documented for one patient (table 1).

During phase two, five patients waited longer than 30 minutes to be thrombolysed. Reasons for delay included contraindication to immediate thrombolysis (hypertension requiring treatment), two equivocal initial ECGs, and for one patient diagnosis was delayed.

The current target times for thrombolysis range from 20-30 minutes. ${ }^{8}$ During phase two, 20 patients in total were treated within 20 minutes (57\%), 13 (37\%) of those arriving by ambulance. During phase one, only 14 patients were treated within 20 minutes (37\%). Of the ambulance arrivals, five (13\%) were thrombolysed within 20 minutes.

It was found that the proportion of phase two patients (21/ 21) arriving by ambulance who received an ECG within the recommended time of ten minutes was significantly greater than the proportion of phase one patients (10/16) (Fisher's exact test, $\mathrm{p}=0.003$ ).

It was also found that the proportion of phase two patients (20/22) arriving by ambulance who received thrombolysis within the guideline based recommended time of 30 minutes was significantly greater than the proportion of phase one patients $(9 / 18)$ (Fisher's exact test, $\mathrm{p}=0.005)$.

The mean DTN time (Table 3) for phase one patients was found to be significantly greater than that for phase two patients (Two sample $t$ test, $\mathrm{p}=0.016$ ). The study results would suggest that a phase one patient could expect to wait on average between 1.6 and 14.6 minutes longer than a phase two patient (95\% confidence interval (CI) mul 1.6 to mu2 14.6) for thrombolysis.

Transformation by taking the natural logarithm normalised time to ECG data (data were back transformed to produce confidence interval). The mean time to ECG (table 4) for phase one patients was found to be significantly greater than that for phase two patients (Two sample $t$ test, $\mathrm{p}=0.008$ ). The study results would suggest that a phase one patient could expect to wait on average between 2.537 and 5.393 minutes longer than a phase two patient (95\% CI mul 2.537 to mu2 5.393) for an ECG.

\section{DISCUSSION}

This study shows that the intervention of introducing an ambulance pre-alert for patients with chest pain improved DTN times. Previous studies have shown that training paramedics in ECG interpretation and diagnosis of AMI improved DTN time, usually by the combination of prealerting the receiving hospital and by fast tracking these patients to CCUs. This study shows that the change in
Table 2 Time to ECG (minutes) for patients pre (phase one) and post (phase two) intervention

\begin{tabular}{|c|c|c|c|c|c|c|}
\hline \multirow[b]{2}{*}{ ECG } & \multicolumn{3}{|l|}{1} & \multicolumn{3}{|l|}{2} \\
\hline & Amb (\%) & Self (\%) & Total (\%) & Amb (\%) & Self (\%) & Total \\
\hline$<10$ minutes & 10 & 13 & 23 & 21 & 7 & 28 \\
\hline$\geqslant 10$ minutes & 6 & 5 & 11 & 0 & 5 & 5 \\
\hline $\begin{array}{l}\text { Not } \\
\text { documented }\end{array}$ & 2 & 0 & 2 & 1 & 0 & 1 \\
\hline Total & 18 & 18 & 36 & 22 & 12 & 34 \\
\hline
\end{tabular}

practice of introducing a pre-alert simply for patients with symptoms suggestive of AMI can significantly reduce DTN times to comply with current national guidelines. Importantly, this relatively simple change should be easy to implement in any A\&E department.

Initial concerns within the department about the change in practice were allayed by the obvious improvement in DTN times. It did not cause an increase in overall workload. In addition, it is popular with the ambulance staff. Further assessment of the number of pre-alert calls made for patients who did not require thrombolysis would be useful to give a more accurate picture of the effect this intervention has had on the day to day running of the department.

However, the validity of the improvement seen may be called into question by the use of an historical control group. This has previously been shown to be associated with an increased estimation of treatment effect. ${ }^{9}$ Obviously staff within the department were aware that DTN targets were not being met. It is difficult to separate the effects increased staff awareness may have had on the improvement in DTN times from the impact of the introduction of the pre-alert call.

Other limitations of this study included the small sample size and incompleteness of the data.

Previous studies have looked at various methods of reducing DTN, such as emergency department thrombolysis, ${ }^{4}$ pre-alert calls for confirmed AMIs, ${ }^{6}$ and pre-hospital thrombolysis. These have shown reductions in DTN times of between $21 \%$ and $51 \%$. This study shows a comparable reduction in DTN times.

Table 3 Comparison of door to needle time (minutes) for ambulance only patients pre (phase one) and post (phase two) intervention

\begin{tabular}{lllll}
\hline Phase & $\mathbf{n}$ & Mean & SD & SE mean \\
\hline 1 & 18 & 27.5 & 11.1 & 2.6 \\
2 & 22 & 19.41 & 9.14 & 1.9 \\
\hline
\end{tabular}

Table 4 Comparison of time to ECG (minutes) for ambulance only patients pre (phase one) and post (phase two) intervention

\begin{tabular}{lllll}
\hline Phase & $\mathbf{n}$ & Mean & SD & SE mean \\
\hline 1 & 16 & 27.5 & 11.1 & 2.6 \\
2 & 21 & 19.41 & 9.14 & 1.9 \\
\hline
\end{tabular}




\section{CONCLUSION}

This study shows that the introduction of an ambulance prealert to A\&E for patients with chest pain produces a substantial reduction in DTN times.

\section{Authors' affiliations}

S R Learmonth, A Ireland, C J Mckiernan, Accident and Emergency

Department, Glasgow Royal Infirmary, Glasgow, Scotland

P Burton, Clinical Audit Department, Glasgow Royal Infirmary,

Glasgow, Scotland

Funding: none.

Competing interests: none declared.

The Corresponding Author has the right to grant on behalf of all authors and does grant on behalf of all authors, an exclusive licence (or nonexclusive for government employees) on a worldwide basis to the BMJ Publishing Group Ltd and its Licensees to permit this article (if accepted) to be published in EMJ and any other BMJPGL products to exploit all subsidiary rights, as set out in our licence (http://emj.bmijournals.com/ misc/ifora/licenceform.shtml).

Ethical approval was not obtained for this study.

\section{REFERENCES}

1 Fibrinolytic Therapy Trialists' Collaborative Group. Indications for fibrinolytic therapy in suspected acute myocardial infarction: collaborative overview of early mortality and major morbidity results from all randomized trials of more than 1000 patients. Lancet 1994:343:311-22.

2 Boersma E, Maas AC, Decers JW, et al. Early thrombolysis treatment in acute myocardial infarction: reappraisal of the golden hour. Lancet 1996; 348:771-5

3 Miller-Craig MW, Joy AV, Adamowicz M, et al. Reduction in treatment delay by paramedic ECG diagnosis of myocardial infarction with direct CCU admission. Heart 1997;78:456-61.

4 Goodacre S, Kelly A-M, Kerr P. Potential impact of interventions to reduce times to thrombolysis. EMJ 2004:21:625-9.

5 Baneriee S, Rhoden WE. Fast-tracking of myocardial infarction by paramedics. J R Coll Physicians of Lond 1998;32:36-8.

6 Corfield AR, Graham CA, Adams JN, et al. Emergency department thrombolysis improves door to needle times. EMJ 2004;21:676-80.

7 Department of Health. National Service Framework for Coronary Heart Disease. London: Department of Health, 2000.

8 Department of Health. Review of early thrombolysis, Faster and better treatment for heart attack patients. London: Department of Health, 2003 , http://www.dh.gov.uk/assetroot/04/06/82/51/04068251.pdf (accessed 1 November 2005).

9 Sacks H, Chalmers TC, Smith H. Randomized versus historical controls for clinical trials. Am J Med 1982;72:233-40. 